\title{
An Experimental Study To Evaluate The Effectiveness Of Music Therapy On Depression Among Elderly In Selected Settings, Vellore,2010-2011
}

\author{
Ms.B.Usharani ${ }^{1}$,Dr.N.Gayathri priya ${ }^{2}$,Dr.G.Balaji ${ }^{3}$, Ms.Susheela Margaret ${ }^{4}$ \\ ${ }^{I}$ Ph.D in Psychiatric nursing student,MAHER University, Chennai \\ ${ }^{2}$ Asst.Professor,Dept of Nursing,University of Bahrain,Kingdom of Bahrain \\ ${ }^{3}$ Chief Radiologist, R.V.S Hospitals, NTR University, Chittoor \\ ${ }^{4}$ Principal, Sri Venkateswara College Of Nursing,NTR University, Chittoor
}

\begin{abstract}
Old age is the most critical stage a person goes through.It is the stage where man faces socially,physically,mentally and even economically.Depression in older adults and the elderly recognizes the sign of getting help.The World Health Organization theme (1993)"handle and prevent violence and negligence"are rightly applicable to geriatric nursing as the nursing world is marching towards quality assurance .Nursing of aged need skill,constant vigilance,observational assessment ,meticulous care planning and efficient nursing care.The World Health Organization called the year 1999 as the international year for the old age with theme"active ageing makes difference"leading to preparation of an active old age. The objective was to evaluate the effectiveness of music therapy on depression among elderly.The study was to conducted at ST.ANNE'S HOME FOR AGED" branch I \&II in vellore district.Simple random sampling technique was used.In two old age homes the investigator selected 30 elders in experimental group and 30 elders in control group. With the help of old age home authorities the investigator conducted a pretest for all the elders in both setting and identified mild and moderate level of depression.Depression scale based on Yesavage Geriatric Depression was developed to evaluate the effectiveness of music therapy in level of depression.The comparison of post test level of depression among elderly between the experimental and control group showed a mean value of 13.2 with S.D 1.6 and 15.1 with S.D 3.2 and ' $t$ ' value 2.8 at $P<0.001$ level of significance.
\end{abstract}

Keywords: Depression,Effectiveness,Elderly,Music therapy

\section{Introduction}

The process of growth starts with the uterine life and ends around pre natal lifge when all linear increments of the body and internal organs fully develop.Almost a decade later the body starts losing all the vital capacities gradually and it is believed to be the onset of ageing.Miller reported that $80 \%$ of the older person are healthy to engage in normal activities the concept of quality life and well-being are increasingly used in recent years in mental health research and wellbeing has both subjective and objective component. Carton(2015)WHO called the year 1999 as the international year for old age with the theme "Active ageing makes the difference"leading to the preparation of active old age .Though it sounds unbelievable but it is true that there are children who leave their old parents as destitute.This had added to the mushrooming of old age homes in india.When the old have to live in the old aged homes inspite of taking care of them they have to go through severe mental trauma.The younger generation should be made aware of the fact that the elderly are an asset to the society and not a burden.

\section{Need For The Study}

WHO(1995) launched a programme on "Age and Health of Elderly" the need of the programme is healthy ageing rather than the elderly living long.It is an achievement that more people will reach old age in good health and capable of contributing to society intellectually,spiritually,physically (Hales 2002).The years between the onset of childhood and elders magnify the trait that can be channeled to music therapy.Waverer Et al(2005)assessed the prevalence of dementia and depression in residents of old age homes in india and the result found one third of the home residents in India $(2004,38.1 \%, 2005,33.5 \%)$ suffered from depression .The prevalence of dementia was significantly higher in old age homes $2004,65.7 \%, 2005,77.5 \%$ )prevalence rates were determined for various socio demographic subgroups sex,age,level of education,marital status and in terms of the limitation on activities of daily living,length of stay,frequency of visits by relatives and friends.In these catchment areas the prevalence rate of both dementia and depression were particularly high among residents who were impaired in their activities of daily living.Mc.Donnall Mc(2009) collected data from a sample of 203 adults aged 55 yrs those who lived in old age homes in India with significantly hearing and vision loss .Social 
factor correlation and hierarchical linear regression were used to analyze the data results indicated that a large proportion of participants experienced depression.

\section{Statement Of The Problem:}

An experimental study to evaluate the effectiveness of music therapy on depression among elderly in selected settings at Vellore district 2010-2011.

\section{Objectives:}

1.To assess the pre test level of depression among elderly in experimental and control group

2.To assess the post test level of depression among elderly in experimental and control group

3.To compare the effectiveness of music therapy among elderly between experimental and control group

4.To associate the effectiveness of music therapy among elderly with their selected demographic variables.

Assumption:

1.Music therapy may have some effect on depression among elderly

Delimitations:

1.The study was delimited to four weeks of data collection at Vellore district

2.The study was delimited to selected old age homes in Vellore district

\section{Research Methodology}

The evaluative research approach was used and the research design selected was true experimental research design the research variables are music therapy (independent variable) and level of depression (dependent variable).Research setting was St.Anne's home for aged and sample of the study were elders between 60-70 yrs of age which comprised 30 samples for experimental group and 30 samples for control group which was selected by using lottery method. The tool consists of part-I demographic variables and part-II depression scale based on yasavage geriatric depression scale

\section{Reliability of the tool :}

The reliability of the tool was established by test retest method .The ' $r$ ' value was 0.9 which indicates a high correlation and the tool was considered highly reliable.

\section{Data analysis procedure}

The data was analyzed in terms of objectives of the study using descriptive and inferential statistics

Descriptive statistics:

Frequency and percentage distribution was used to analyze the socio demographic data and for elders mean and standard deviation was used to assess the depression

\section{Inferential statistics:}

' $t$ ' test was used to find the significant difference in pretest and posttest level in experimental and control group .Chi-square test was used to associate the level of depression with the socio demographic variables.

\section{Results And Findings}

Table 1 :Frequency and percentage distribution of pretest level of depression among elderly in experimental and control group

\begin{tabular}{|l|l|l|l|l|}
\multicolumn{4}{|c|}{ n=60 } \\
\hline Depression level & Experimental group & Control group & Percentage $(\%)$ \\
\hline Mild & Frequency & Percentage $(\%)$ & Frequency & 66.7 \\
\hline Moderate & 22 & 73.3 & 20 & 33.3 \\
\hline
\end{tabular}

Figure 1:Percentage distribution of pretest level of depression among elders in experimental and control group

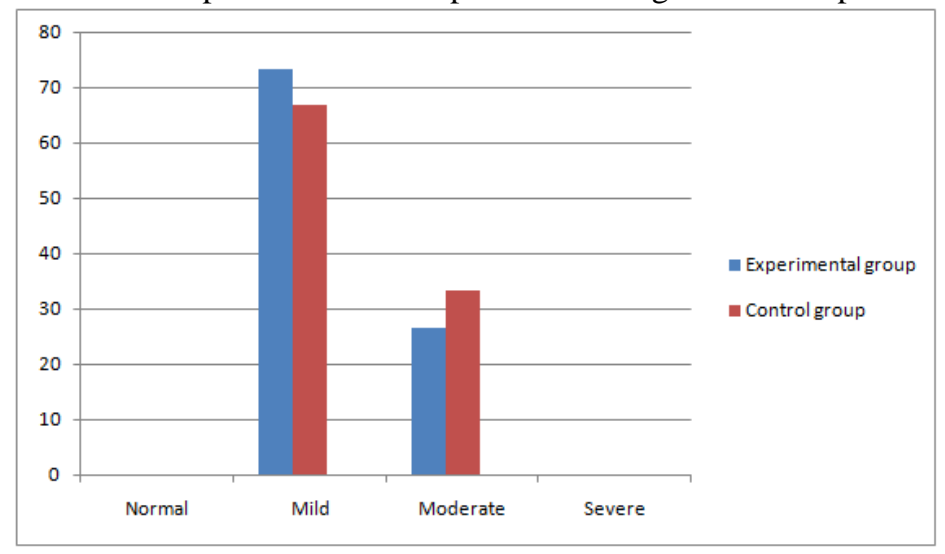


An Experimental Study To Evaluate The Effectiveness Of Music Therapy On Depression Among..

Table 2:Frequency and percentage distribution of post test level of depression among elderly in experimental and control group

\begin{tabular}{|l|l|l|l|l|}
\multicolumn{5}{|c|}{ n=60 } \\
\hline Depression level & Experimental group & Control group \\
\hline & Frequency & Percentage(\%) & Frequency & Percentage(\%) \\
\hline Mild & 29 & 96.7 & 21 & 70.0 \\
\hline Moderate & 1 & 3.3 & 9 & 30.0 \\
\hline
\end{tabular}

Figure 2:Percentage distribution of pretest level of depression among elders in experimental and control group

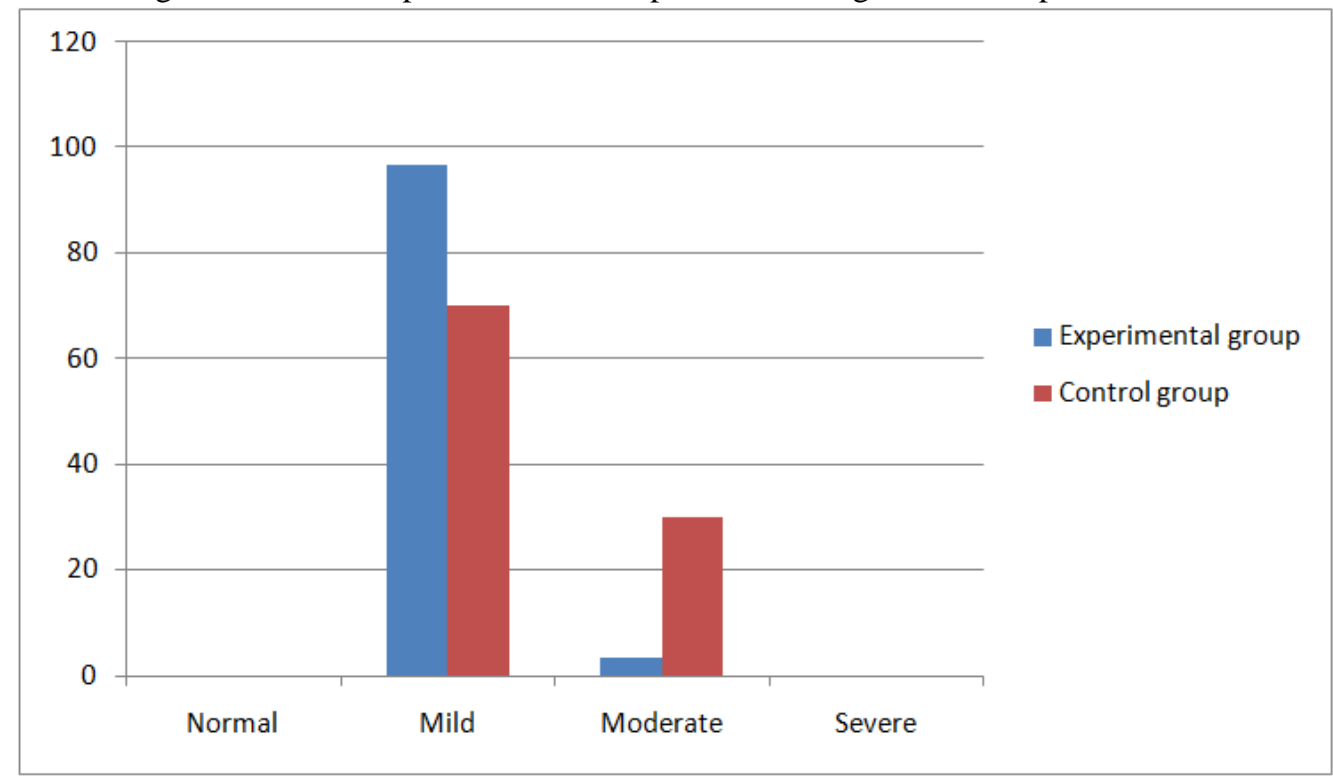

Table 3:Comparison of effectiveness of music therapy among experimental and control group

\begin{tabular}{|l|l|l|}
\hline \multicolumn{2}{|c|}{ n=60 } \\
\hline i)Pre test score mean/SD & Experimental group & Control group \\
\hline ii)Post test score mean/SD & $14.9 / 3.9$ & $15.3 / 3.5$ \\
\hline iii)Effectiveness pre-post score difference \&mean difference & $13.2 / 1.6$ & 1.4 \\
\hline SD & 2.7 & $15.1 / 3.2$ \\
\hline 't' (Paired) & 2.8 & 0.2 \\
\hline Statistical Significance & $\mathrm{P}<0.001$ & 3.1 \\
\hline
\end{tabular}

Figure 3:Distribution of mean score of pre \&post test level of depression in the experimental group

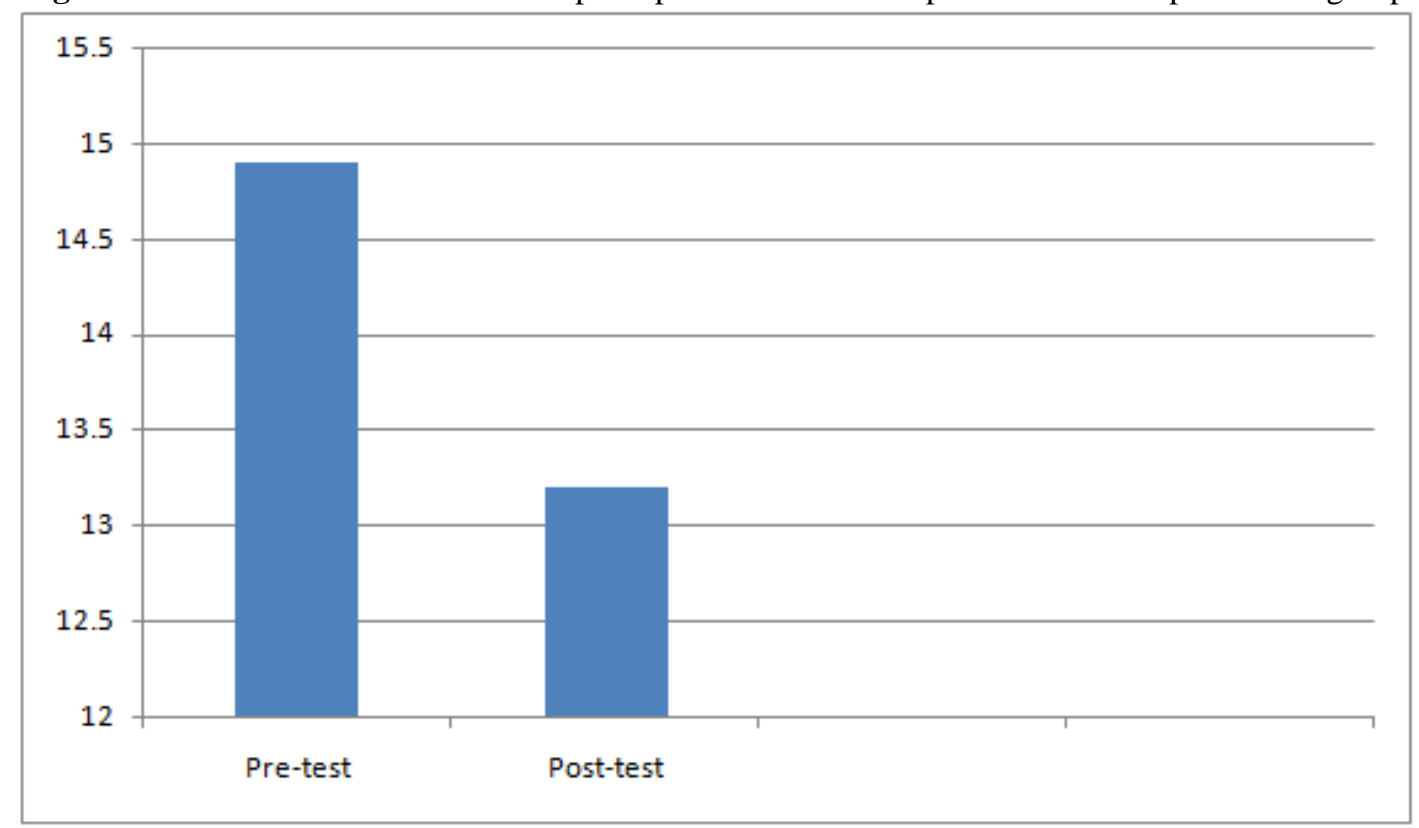




\section{Nursing Implications}

Nursing practice: The psychiatric nurses have a vital role in enabling effective identification of depression and minimize the level of depression by music therapy.This can be facilitated by motivating the nurse to

(1) Learn about identification and management of depression among elderly

(2) Teach family members, old age home workers \& authorities about the identification and management of depression with music therapy

\section{Nursing education:}

(1) Ensure the students learn about prevalence, identification and management of depression

(2) Provide adequate clinical exposure to the students in different settings of elders with depression

(3) Arrange for workshops for students to participate so that they gain knowledge about music therapy and depression

(4) A psychiatric nurse should participate in specialized courses in depression assessment using depression scale

(5) Make available literature related music therapy and depression in library for students reference

Nursing administration:

(1) Collaborate with governing bodies in formulating policies to employ specially qualified nurse in psychiatric unit to supervise the teaching programme

(2) Conduct in service education programme in identification and management of depression and application of music therapy in various fields

(3) Provide opportunity for nurses to attend training programme on identification and management of depression

(4) Improve data on identification and management of depression on elderly in various settings

\section{Nursing research:}

(1) Encourage further studies on effectiveness of music therapy on depression among medical conditions and other settings

(2) A evident from the review of literature more research should be conducted on the management of depression

\section{Recommendations:}

(1) A similar study can be conducted with larger sample

(2) A similar study can be conducted in various settings

(3) A similar study can be conducted on other age groups

\section{Conclusion}

The following conclusions were drawn on the basis of present study

(1) The findings showed that pretest mean score was 14.9 and after music therapy the posttest mean score was 13.2 it showed that the depression level of elders were reduced after music therapy

\section{Acknowledgement}

I express my heartfelt thanks to our respected principal Prof.Mrs.Anuradha-Vel.R.S.Medical CollegeCollege of Nursing whose guidance and support enabled me to do the work I also express my sincere thanks to Ms.K.Sudha devi .,Vice-Principal- Vel.R.S.Medical College-College of Nursing for her expert suggestions and guidance.Above all from the depth of my heart I thank my beloved parents for their strength which sustained me through ups and downs of this study a reality.

\section{References}

[1]. Ahuja Niraj.(2002),A short textbook of psychiatry $\left(5^{\text {th }}\right.$ edition).Newdelhi:jaypee medical publisher(P) ltd

[2]. Burke M \& Walsh B.M(1997) Gerontologic nursing( $2^{\text {nd }}$ edition $)$ London:Mosby publication

[3]. Stuart and sundren .N (1993):principles and practice of psychiatric nursing( $4^{\text {th }}$ edition).Toronto:Mosby company

[4]. VandenBerg JF et al(2009), sleep in depression and anxiety disorders among elderly persons,journal of clinical psychiatry,123-134

\section{Rape trauma syndrome}

Rape trauma syndrome (RTS) is the psychological trauma experienced by a rape victim that includes disruptions to normal physical, emotional, cognitive, and interpersonal behavior. The theory was first described by psychiatrist Ann Wolbert Burgess and sociologist Lynda Lytle Holmstrom in 1974. 


\section{II.Phases of RTS}

1. Acute Phase: This phase occurs immediately after the assault, and usually lasts a few days to several weeks. In this phase, individuals can have many reactions, but they typically divide into three categories of reactions:

(a)Expressed - This is when the survivor is openly emotional. He or she may appear agitated or hysterical; he or she may suffer from crying spells or anxiety attacks.

(b)Controlled - This is when the survivor appears to be without emotion, and acts as if "nothing happened" and "everything is fine." This appearance of calm may be shock.

CShocked Disbelief - This is when the survivor reacts with a strong sense of disorientation. He or she may have difficulty concentrating, making decisions, or doing everyday tasks. He or she may also have poor recall of the assault.

2. The Outward Adjustment Phase: During this phase, the individual resumes what appears to be his or her "normal" life, but inside is suffering from considerable turmoil. In this phase, there are five primary coping techniques:

(a)Minimization — Pretends that "everything is fine" or that "it could have been worse."

(b)Dramatization - Cannot stop talking about the assault, and it is what dominates one's life and identity.

(C) Suppression - Refuses to discuss, acts as if it did not happen.

(d)Explanation - Analyzes what happened: what the victim did, what the rapist was thinking/feeling.

(e)Flight - Tries to escape the pain (moving, changing jobs, changing appearance, changing relationships, etc.).

There are many symptoms or behaviors that appear during this phase, including:

1. Continuing anxiety

2. Severe mood swings

3. Sense of helplessness

4. Persistent fear or phobia

5. Depression

6. Rage

7. Difficulty sleeping (nightmares, insomnia, etc.)

8. Eating difficulties (nausea, vomiting, compulsive eating, etc.)

9. Denial

10. Withdrawal from friends, family, activities

11. Hypervigilance

12. Reluctance to leave house and/or go places that remind the individual of the assault

13. Sexual problems

14. Difficulty concentrating

15. Flashbacks

3. The Resolution Phase: During this phase, the assault is no longer the central focus of the victim's life. While he or she may recognize that he or she will never forget the assault, the pain and negative outcomes lessen over time. Often, the individual will begin to accept the rape as part of his or her life, and choose to move on.

\section{III.Treatment of RTS}

Know that this was not your fault. No matter how it happened, nothing you did caused someone else to rape or sexually assault you

1. Do not be afraid of telling people for fear of being blamed. It was not your fault. Your body belongs to you and only you.

2. Rape and sexual assault can happen to anyone, anywhere. Men are victims, too

3. You never asked for it, no matter what you were wearing, and you're not alone.

4. Being forced into sex or being sexually assaulted by someone you are on a date with is still acquaintance or date rape. It doesn't matter if you know them and are dating them. You can be in a regular relationship with someone and still be forced into having sex against your will, even if it's not a violent act. More than half of all rapes are by someone you know.

5. Drinking alcohol or taking drugs is not an excuse for someone to rape you. Intoxication loosens inhibitions and can increase violent tendencies. Drugs and alcohol can also decrease your ability to get help. Regardless of who was drinking or taking the drugs, there is still no excuse for sexual assault.

6. If you are a male and you had an erection during the assault, do not be ashamed or feel guilty as if you enjoyed it. An erection is simply a natural physical reaction to stimulation even if you didn't want it and didn't enjoy it. You were not asking for it. 
Do not shower, wash up, or change your clothes. You naturally will feel the need to get any trace of the perpetrator off of you but it is important that you wait. Any bodily fluids or traces of hair left on you from your assailant can be used later as evidence, if you decide to press charges.

Washing your face, body, or clothes can remove vital evidence.

Get immediate medical attention. Go to the hospital and inform the staff you have been assaulted and tell them if the assault included vaginal or anal penetration. If you permit them, specially trained staff will conduct a "forensic exam" and use a "rape kit" to collect hair and fluid samples for forensic evidence. Their training ensures that they are sensitive to your feelings and needs in this terrible time and they try to make the process as bearable as possible. You might need to be tested and/or treated for sexually transmitted infections and pregnancy. Treatment might include emergency contraception and prophylactic medication to prevent sexually transmitted infections.

Inform staff if you suspect you were drugged or assaulted while under the influence of alcohol.

If you suspect a date rape drug was used, try not to urinate until you get to the hospital, as they will request a urine sample to test for Rohypnol and other date rape drugs. Many sexual assault centres provide trained staff to accompany you to a hospital or medical appointment so you don't have to go alone.

Consider calling the police to report the incident.Informing police can bring your perpetrator to justice and prevent him from harming anyone else If you suspect you were drugged save any cups or bottles that you drank out of, if possible,drug testing may be conducted to confirm use of the drug and provide evidence that can be used later. The most common date rape drug is Rohypnol-its alcohol .Tell the police if alcohol or drugs were involved even if you willingly drank alcohol or took drugs before you were assaulted it is never your fault.Informing police also has the psychological advantage of helping you transition from victim to survivor. Don't hesitate to act if time has passed.Even if the rape occurred more than 72 hours ago, it is still imporatant for you to contact the police, a help line and a medical professional evidence of bodily fluids is best collected within 72 hours of the assault.Even if you are not sure you are going to press charges get the evidence collected so it is there if you need it

Hold on through the emotional trauma.You have gone through an event that will likely cause shock,depression,anxiety,fear and hypervigilance and nightmares this is normal and it will be better.Survivors also feel guilt and shame, suffer disturbed eating and sleeping pattern and have trouble focusing

Understand you will have physical symptoms. You might be suffering pain,cuts, bruising,internal injuries or irritation from the assault.These painful symptoms remind but they will pass through by having hot bath, meditating or other relaxation techniques.

Expect a period of denial and repression. Denying and repressing your feelings is a completely normal part of the second phase of healing, which is called the Outward Adjustment phase. These actions serve significant important roles in the coping and healing process. A survivor often goes through a phase of acting as if the sexual assault had no effect on her life and it was just a bad sexual experience. This act of denying and repressing is called minimization and is a normal response to help you carry on in the short term.

Try to get on with life for a while. A survivor needs to restore a sense of normalcy in her life.This part of the Outward Adjustment phase is called suppression and allows you act as if the assault didn't happen, though you still have turmoil inside. Just like the minimization part of this phase, suppression allows you to carry on in the short term.

Talk about it, if you can and want to. You might feel the need to talk about the assault and how you feel to family, friends, help lines, and therapists. This is a normal coping technique called dramatization but that does not mean you are making a "drama" out of nothing. You may feel like the trauma has taken over your life and is changing your identity, especially if all you can and want to do it talk about it. It's normal to need to get it out.

Allow yourself to analyze it. Sometimes, a survivor needs to analyze what happened and try to explain it to herself or others. You might even put yourself into the shoes of the perpetrator to see if you can imagine what he was thinking. This does not mean you are empathizing with the perpetrator or somehow excusing his behaviour, so you do not need to feel guilt if you find yourself going through this phase.

Don't talk about it if you don't want to. You have the right to not talk about the assault if you don't feel like it, even if you know family and friends are just trying to help by suggesting you talk about it. Sometimes, survivors may even change jobs, move cities, or change friends to avoid emotional triggers and talking about the incident. Not every survivor feels this need. This part of the phase is called flight because some survivors feel the desire to run away from their pain.

Allow yourself to feel your feelings. The depression, anxiety, fear and hypervigilance, nightmares, and rage you experience are all normal symptoms of having been sexually assaulted.During this time you might be reluctant to leave the house, have trouble eating and sleeping, and withdraw from people and society. 
Let the pain flow. In the third and final stage of rape trauma, survivors often find the memories of the event flooding back and can no longer repress it. This is where the healing really begins.

You might be having flashbacks so intrusive that they disrupt your life. These are normal post-traumatic stress and rape trauma reactions.

Know that it gets better. This is often the stage where survivors feel overwhelmed, suffer flashbacks, and contemplate suicide. As horrible as these feelings are, this is when you can begin to instead integrate the past into a new reality and carry on- You will at some point accept that the rape was part of your life and you can move forward.

Involve family and friends. This is the time for you to regain your sense of safety, trust, and control, and you need to be in contact with others for this to happen Choose when, where, and with whom you share your experience of violence. Be with people who are supportive and set limits by only discussing what you feel comfortable discussing.

Get support from a professional. A counsellor specially trained in dealing with rape and sexual trauma can be an empathetic person to help you work through your emotions.

There are also specific group therapy meetings and even online chat rooms for survivors. Find what works for you

Give yourself time to heal. It may take several months. It may take several years Over time, you will be redefining yourself, your worldview, and your relationships. Be kind to yourself and don't expect to heal overnight.

Get help with pursuing court charges and legal action. If you are unsure of what to do next, call your local crisis centre for assistance. Their staff are trained to guide you through the process and can attend meetings and appointments with you if you want. You do not have to press charges if you do not want to. Police can also warn the perpetrator to try to prevent him from doing it again.

You may be entitled to financial assistance for some of the expenses associated with missing work, going to court, getting counselling and more. Check with your local crisis centre for more information. Many crisis centres have links or free, legal aid specifically for survivors of sexual assault. At these centres, support workers may also be available to accompany you to meetings with lawyers or to court.

Know the law. Sexual assault is not subject to a statute of limitations, which means that even if your assault occurred months or years ago, you can still report it to the police. If you choose to press charges against the perpetrator and you had received medical attention soon after the assault, there is a good chance that evidence was collected. If the doctor or nurse used a "rape kit" or did a "forensic exam," there is evidence safely stored on file that police can then examine. 